\title{
TROPICAL DISEASES AND PUBLIC HEALTH
}

THE PREVENTION OF SPIT-BORNE DISEASES

Bi ENNion G. Williams, M.D., Commissioner of Health of Virginia, Richmond, Va.

Among the preventable communicable diseases some require for their control community action, others demand attention to the personal habits of the individual. To make this clear, the filth-borne diseases, such as typhoid, can not be prerented absolutely without definite action on the part of the community, safeguarding its water supply and requiring sewerage or sanitary privies. To the contrary, the spit-borne diseases demand for their prevention the action of the individual.

No law, however carefully drawn or supplied with penalties for infractions, will serve to make every individual cover his nose or mouth when he coughs or sneezes; and unless this result is achieved the air will be sprayed with droplets containing infection from the man who does cough or sneeze into it.

When these droplets get into the air and are there held in suspense, it is virtually impossible to prevent some other individual from inhaling the infectious droplets or getting them into the eye, there to travel through the tear duct into the respiratory tract. As a consequence, the health officer can not hope to make rapid progress in the prevention of influenza, measles, whooping cough and the other spray-borne spit diseases. The progress is necessarily slow; it can be accomplished only by education, and the habits of generations do not yield rapidly.

On the other hand, the prevention of non-spray-borne spit diseases offers a less exacting problem, and one that promises a little more speedy solution. This group of diseases, which includes diphtheria and scarlet fever, has virtually no coughing nor sneezing; and, to be infected. the secretions from the mouth or nose of a case or carrier would actually be carried into the nose or mouth of a victim. The germ is not suspended into the air like the spray-borne germs.

This being true, it would seem that the problem of control is not so difficult. The incidence of these diseases can be almost mathematically reduced when children are male to give up the bad habit of putting into their nouths fingers or pencils that might be soiled by the spit of others, and the particularly bad habit of using a common drinking cup. But to be effective these habits must be avoided utterly, for

\section{SAVE YOURSELF From MENNGGTIS} $\begin{array}{lcl} & \text { AND ALSO FROM } \\ \text { DIPHTHERIA } & \text { BAD COLDS } & \text { TUBERCULOSIS } \\ \text { SCARLET FEVER } & \text { GRIPPE } & \text { MEASLES } \\ \text { SORE THROAT } & \text { TONSILITIS } & \text { PHOOPING COUGH } \\ \text { MUMPS } & & \text { PNEUMNIA }\end{array}$

\section{Follow Two Simple Rules}

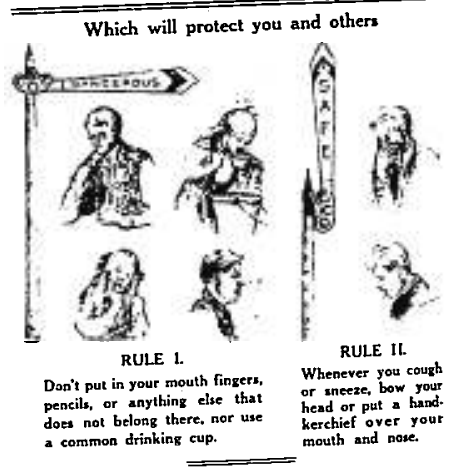

The Germs of these Diseases are spread through the secretions of the mouth and nose of sick people and carriers

POSTED BY THE STATE BOARD OF HEALTH.

there are several times as many carriers and mild unrecognized cases as there are clearly defined and recognized clinical cases, so that what may not seem to be a source of danger might actually be a menace.

As the chances for getting the infection 
is reduced, the incidence of the diseases should be reduced proportionately. As with the safety-first movement that has accomplished such wonderful results, the prevention of diseases like the prevention of accidents is accomplished by the avoidance of small risks. There is small risk in putting the fingers or common cups to the mouth as there is small risk in stepping off or on a moving car, yet when these risks or the chances of incurring accidents are reduced, the incidence of disease or accidents is reduced in the same

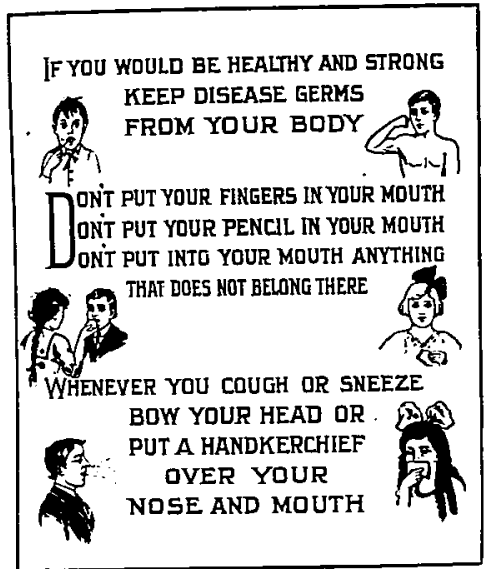

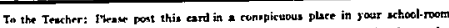

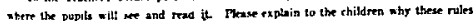

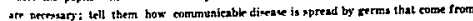

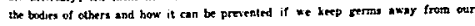
nimulthe and toms.

If yiu can art youf propils to neactice these simpie rules you will find a sharp de-

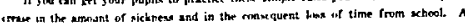

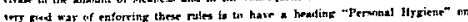

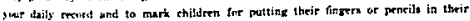

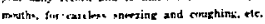
biesy reepectfults.

ENSIOS t: WIt.LAMS situte liezlth Commigainger.

proportion. In an effort to reduce the spit-borne diseases, the State Board of Health sent to the school teachers of Virginia at the beginning of the sessions 1916-1917-1918 placards, as shown in the accompanying cuts, and urged the enforcement of these simple principles, and at the

same time special efforts were made to enforce law prohibiting the use of the common cup in the schools.

The following tables show the morbidity and mortality from diphtheria and scarlet fever for the years the statistics

\section{SAVE YOURSELF

\begin{tabular}{lll}
\hline DIPHTHERIA & BAD COLDS & TUBERCULOSIS \\
SCARLET FEVER & GRIPPE & MEASLES \\
SORE THROAT & TONSILITIS & $\begin{array}{l}\text { WHOOPINC COUGH } \\
\text { MUMPS }\end{array}$ \\
MENINGITIS & PNEUMONIA \\
SPANISH GRIPPE &
\end{tabular} \\ Follow Two Simple Rules}

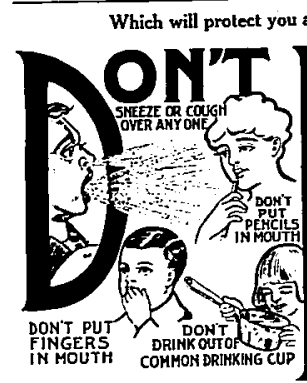

RULE I

Don't put in your mouth fingers, pencily, or anything else that does not belong there, nor use a cornmon drinking cup The Germs of these Diseases are spread through the secretions of the mouth and nose of sick people and carriers.

$$
\text { VIRCINU STATE BOARD OF HEALTH }
$$

are available. The asterisks mark the year following the first sending out the placards, 1916, the fiscal year beginning with October:

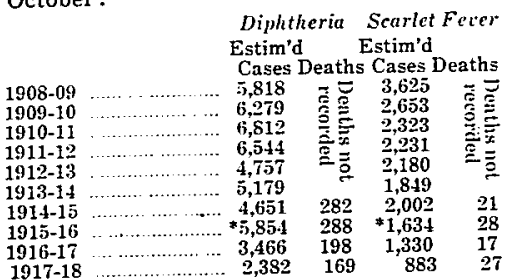

